\title{
Gastric-Type Mucinous Adenocarcinoma of the Cervix in A Woman With Peutz-Jeghers Syndrome
}

\section{tong tong ( 18017310267@163.com )}

International Peace Maternity and Child Health Hospital https://orcid.org/0000-0002-9702-7984

\section{Qiong Fan}

International Peace Maternity and Child Health Hospital

\section{Shu Shi}

International Peace Maternity and Child Health Hospital

\section{Yuhong Li}

International Peace Maternity and Child Health Hospital

\section{Yudong Wang}

International Peace Maternity and Child Health Hospital

\section{Case report}

Keywords: Peutz-Jeghers syndrome, gastric-type adenocarcinoma, cervix, HPV

Posted Date: January 21st, 2021

DOI: https://doi.org/10.21203/rs.3.rs-150876/v1

License: (c) (1) This work is licensed under a Creative Commons Attribution 4.0 International License. Read Full License 


\section{Abstract}

Background: Peutz-Jeghers syndrome(PJS) is a very rare autosomal dominant disorder with predisposition to multiple neoplasms. Gastric-type adenocarcinoma (GAS) is a less common carcinoma of the cervix than squamous cell carcinoma, which is more aggressive and has lower 5 year survival rate than usual type endocervical adenocarcinoma (ECA), and unrelated to human papilloma virus(HPV) infection as well. We present a 32 year-old patient with Peutz-Jeghers syndrome who was found to have gastric-type adenocarcinoma of the cervix.

Case presentation: A 32-year-old woman without sexual life ever who was diagnosed Peutz-Jeghers syndrome when she was two years old presented with watery discharge for more than 6 months. A tumor around $6 \mathrm{~cm}$ was found on the cervix and she was diagnosed gastric-type mucinous adenocarcinoma of the cervix clinical stage IB3. She was treated with artery intervention chemotherapy for one course followed by radical surgery and then systematic chemotherapy.

Conclusions: The case suggests more thorough cancer screening for patients with PJS as the disorder is rare and has high risk of malignancies. Young patients with Peutz-Jeghers syndrome, including those without sexual life, who have watery discharge or bleeding should be screened for cervical carcinoma even if cytologic results or human papilloma virus (HPV) is negative.

\section{Backgroud}

Peutz-Jeghers syndrome is a rare autosomal dominant disorder characterized by mucocutaneous pigmentation, multiple hamartomatous polyps in the gastrointestinal tracts and predisposition to certain neoplasm ${ }^{1}$. The estimated incidence ranges from 1 in 50,000 to 1 in 200,000 live births ${ }^{1,2}$. Previous reports ${ }^{3,4}$ shows that $11-17 \%$ of women with Peutz-Jeghers syndrome are found to have gastric-type adenocarcinoma (GAS). We report a case of adenocarcinoma of the cervix, diagnosed by cervical biopsy in a woman with Peutz-Jeghers syndrome, which was eventually histo-pathologically confirmed to be GAS after radical surgery.

Adenocarcinoma of the cervix is less common than squamous cell carcinoma of the cervix. However, the incidence of cervical adenocarcinoma has been increasing, especially in young women and is estimated to account for up to $10 \%-25 \%$ of all invasive cervical carcinomas ${ }^{5}$. Gastric-type adenocarcinoma (GAS) is a novel variant of endocervical mucinous adenocarcinoma according to the 2014 WHO classification ${ }^{6}$. It represents more aggressive disease and poorer prognosis than the usual-type endocervical adenocarcinoma (UEA) 7,8 .

\section{Case Presentation}

The institutional review board (International Peace Maternity and Child Health Hospital) approved this work. A 32-year-old woman without sexual life ever presented with a history of recurrent watery vaginal 
discharge for more than 6 months and prolonged menstrual periods over the preceding 3 months in August 2020. Pelvic magnetic resonance imaging (MRI) revealed a cervical mass $5.8 \star 5.6 * 7.6 \mathrm{~cm}$ while enlarged lymph nodes were not seen (Fig. 1A and 1B). The patient was diagnosed Peutz-Jeghers syndrome at 2 months old at a tertiary hospital for mucocutaneous pigmentations over the lips. She had a history of colon polyps resection by colonoscopy when she was 12 years old and since then had colonoscopy and biopsy every year. In 2002 when she was 14 years old, she had an emergent surgery for bowl obstruction. In 2018 she had a surgery for breast tumor and pathology confirmed benign. No other family members were found with Peutz-Jeghers syndrome.

Physical examination revealed mucocutaneous pigmentations over the lips, especially the lower lip and nostrils (Fig. 2). Laboratory data showed no blood, urine, or stool changes. HPV test was negative. Tumor markers including carbohydrate antigen125(CA125), carbohydrate antigen199(CA199), squamous cell carcinoma antigen(SCC), carbohydrate antigen153(CA153), carbohydrate antigen724(CA724), carcinoembryonic antigen(CEA), alpha fetoprotein(AFP) and human epididymis protein4(HE4) were within normal range.

We proceeded with a gynecological examination under anesthesia. A tumor around $6 \mathrm{~cm}$ was found on the cervix, vagina and parametrium was not invaded on physical examination. Biopsy was taken and paraffin section pathology diagnosed moderate differentiated gastric-type mucinous adenocarcinoma of the cervix.

In accordance with the latest 2018 International Federation of Gynecology and Obstetrics criteria, gastrictype mucinous adenocarcinoma of the cervix clinical stage IB3 was diagnosed. We gave her artery intervention chemotherapy for one course ${ }^{9,10}$ (intravenous taxol $135 \mathrm{mg} / \mathrm{m}^{2}$ and bilateral uterine artery cis-platinum $80 \mathrm{mg} / \mathrm{m}^{2}$ ). MRI was taken 2 weeks later for tumor assessment. On the second MRI, the tumor shrinked to $4+\mathrm{cm}$, and there were some dartoid tissue fell out of vagina one week after the artery intervention chemotherapy told by the patient.

Eventually, the patient underwent laparoscopic radical hysterectomy, bilateral salping-oophorectomy, bilateral pelvic lymph node dissection and para-aortic lymph node dissection 3 weeks after the artery intervention chemotherapy. The final histo-pathological analysis of the specimen from radical surgery confirmed moderate differentiated cervical gastric-type mucinous adenocarcinoma (Fig. 3A and Fig. 3B). No myometrial invasion or metastasis to pelvic lymph nodes was observed, no lymphovascular space invasion and clear vaginal resection margins. Immuno-histochemistry shows MUC6(+), MUC2(-), P16 patchy, ER and PR all negative(Fig. 4A-4F). A gene test was also taken and a mutation of STK11 was confirmed. The patient had adjuvant chemoradiation therapy after the radical surgery: intravenous taxol $\left(135 \mathrm{mg} / \mathrm{m}^{2}\right.$ every 21 days) and carboplatin (area under the curve of concentration*time[AUC] = 5 every 21 days). We plan to give her 6 courses of intravenous chemotherapy in total and right now she already has 5 courses and tolerates well.

\section{Discussion And Conclusions}


Peutz-Jeghers syndrome (PJS) is a clinical syndrome, occurring in sporadic and in autosomal dominant inherited forms, usually characterized by gastrointestinal, especially small bowel, hamartomatous polyposis, mucocutaneous melanin pigmentation and predisposition to certain neoplasms ${ }^{11}$. The first systematic descriptions of the inherited form of PJS are credited to Drs Jan Peutz and Harold Jeghers, who both described patients with gastrointestinal hamartomatous polyps and mucocutaneous melanin pigmentation-the latter distinguishing PJS from other gastrointestinal polyposis syndromes ${ }^{12,13}$. PJS affects about 1 in 50,000 to 200,000 individuals. Right now PJS is diagnosed by clinical criteria in a proband with one of the following, based on a European consensus statement ${ }^{14}$. Two or more histologically confirmed PJS-type hamartomatous polyps; Any number of PJS-type polyps detected in one individual who has a family history of PJS in at least one close relative; Characteristic mucocutaneous pigmentation in an individual who has a family history of PJS in at least one close relative; Any number of PJS-type polyps in an individual who also has characteristic mucocutaneous pigmentation.

PJS is a rare autosomal dominant syndrome defined by germline mutation of STK11 (chromosome 19p13.3) which encodes a serine/threonine kinase involved in cell polarity, metabolism and growth ${ }^{15}$. Germline mutation of STK11 is detected in $94 \%$ of PJS patients ${ }^{16,17}$. In this case, the patient was found STK11 mutation on chromosome 19 in exon 4. Until now a variety of deletion, insertion, inversion, and nonsense mutations have been described in nearly every coding exon, predominately in exons $1,5,6$, and $7^{18,19}$. However, right now data on genotype-phenotype correlation related to STK11 pathogenic variants are conflicting. The major source of morbidity and mortality, besides intestinal intussusception in young patients, is the increased lifetime risk of cancer, the most common being breast, colon, pancreatic, gastric, small intestine and lung cancer, the cumulative risks were seen in table $1^{1}$. PJS-specific cancer surveillance guidelines exist, see table $2^{1}$.

1. If significant polyps are present at baseline, repeat upper endoscopy/colonoscopy every three years. If no significant polyps are present at baseline, repeat at age 18 years and then every three years.

2. CT enterography may be used as an alternative. The use of MR enterography allows for simultaneous surveillance for pancreatic cancer.

3. If few or no polyps at baseline, repeat at age 18 years.

4. Digital mammography if MRI not available

5. Discuss prophylactic mastectomy.

6. Discuss prophylactic hysterectomy and oophorectomy.

Gynaecological tumours are not a major manifestation of PJS but there are two with distinct pathological features $^{20}$ : (1)gastric-type adenocarcinoma of the endocervix (GAS) and (2) ovarian sex cord tumour with annular tubules (SCTAT). Much less commonly, ovarian oxyphilic Sertoli cell tumour may occur in PJS patients $^{21}$. One meta-analysis of the literature estimated the lifetime risk of cervical cancer in PJS to be 
$9 \%$ and mean age at diagnosis in the third decade ${ }^{20}$. Most cases were so-called adenoma malignum (also known as minimal deviation adenocarcinoma, MDA), which is now considered to be equivalent to a well-differentiated form of GAS in the 2014 World Health Organization(WHO) classification system. On the other hand, among those who have GAS, about $11-17 \%$ have PJS 22,23 . Ovarian tumors occur in about $21 \%$ of PJS patients, most of which are SCTAT ${ }^{24}$.

The diagnosis of gastric-type adenocarcinoma is based on the histological criteria $25,26: 1$ ) clear or pale eosinophilic cytoplasm, 2) voluminous cytoplasm, and 3) distinct cell borders. The immune-phenotype of GAS is defined by the presence of pyloric gland mucin (positive MUC6 and HIK1083 staining) and by the absence of high risk HPV(hrHPV) $16^{27-30}$, MUC6 is more widely available than HIK1083, both of which mark pyloric gland mucin of the stomach and are positive in most GAS and lobular endocervical glandular hyperplasia(LEGH) but not in normal endocervix or usual type endocervical adenocarcinoma(ECA $)^{8,11}$. p16 staining is usually patchy or negative. Most GAS lack estrogen receptors, and is unrelated to HPV infection, as shown in our case.

The presenting sign of GAS is often mucoid or watery discharge or vaginal bleeding, and typically shows widespread involvement and advanced stage at initial diagnosis. Ovarian involvement is not uncommon as well. GAS is more aggressive than usual type ECA; the 5 year survival rate is less than half of that for usual type $\mathrm{ECA}^{31,20}$. The prognosis of patients with GAS is worse than that of patients with HPV-related adenocarcinoma because patients with GAS tend to represent an advanced-stage disease and unusual metastatic organs. So in our case, we suggested and finally performed bi-oophorectomy for the patient under her consent. In the meanwhile, as according to the 2018 LACC clinical trial, we improved the surgical procedures of laparoscopic radical hysterectomy. In the surgery, a tape was used for uterus manipulation instead of cup-type uterine trans-cervical manipulator; In addition, colpotomy was done vaginally and the uterus was taken out from the vagina with the cervix wrapped in the vaginal wall cut.

Because of the high risk of malignancy in Peutz-Jeghers syndrome, a more thorough cancer screening has been proposed. Annual pelvic sonography and cervical screening test have been recommended for cancer screening in females with Peutz-Jeghers syndrome ${ }^{11,20,1}$. Although cytologic or HPV tests are usually negative in GAS, the presence of an enlarged cervix with multiple cysts in a patient with PeutzJeghers syndrome is an indication for cervical biopsy even if the patient has no sexual life.

\section{Abbreviations}

PJS

Peutz-Jeghers syndrome

GAS

gastric-type adenocarcinoma

ECA

endocervical adenocarcinoma

HPV 
human papilloma virus

UEA

usual-type endocervical adenocarcinoma

MRI

magnetic resonance imaging

CA125

carbohydrate antigen 125

CA199

carbohydrate antigen199

SCC

squamous cell carcinoma antigen

CA153

carbohydrate antigen 153

CA724

carbohydrate antigen 724

CEA

carcino-embryonic antigen

AFP

alpha fetoprotein

HE4

human epididymis protein4

AUC

area under the curve of concentration

SCTAT

sex cord tumour with annular tubules

MDA

minimal deviation adenocarcinoma

WHO

World Health Organization

LEGH

lobular endocervical glandular hyperplasia

\section{Declarations}

- Ethics approval and consent to participate

The institutional review board (International Peace Maternity and Child Health Hospital) approved this work

- Consent for publication 
Informed consent for publication of clinical data/details/images was obtained from patient. A copy of consent is available for review by the Editor of this journal

- Availability of data and materials

There is no dataset as this is a case report. Data/details of the patient available upon request

- Competing interests

The authors declare that they have no competing interests

- Funding

This research did not receive any specific grants or funding

- Authors' contributions

TT: writing of the manuscript. FQ: providing the case details. SS: providing the case details. LYH: writing and editing of the manuscript. WYD: editing of the manuscript. The authors read and approved the final manuscript

- Acknowledgements

We thank Professor Huijuan Zhang for providing pathology information and guidance of the case.

\section{References}

1. McGarrity TJ, Amos Cl, Baker MJ. Peutz-Jeghers S. 2001 Feb 23 [Updated 2016 Jul 14]. In: Adam MP, Ardinger $\mathrm{HH}$, Pagon RA, et al., editors. GeneReviews ${ }^{\circledR}$ [Internet]. Seattle (WA): University of Washington, Seattle; 1993-2020.

2. Burt RW. Polyposis syndromes. Clin Perspect Gastroenterol. 2002;5:51-9.

3. Young RH, Welch WR, Dickersin GR, Scully RE. Ovarian sex cord tumor with annular tubules: review of 74 cases including 27 with Peutz-Jeghers syndrome and four with adenoma malignum of the cervix. Cancer. 1982;50:1384-402.

4. Gilks CB, Young RH, Aguirre P, DeLellis RA, Scully RE. Adenoma malignum (minimal deviation adenocarcinoma) of the uterine cervix. A clinicopathological and immunohistochemical analysis of 26 cases. Am J Surg Pathol. 1989;13:717-29.

5. Adegoke O, Kulasingam S, Virnig B. Cervical cancer trends in the United States: a 35-year populationbased analysis. J Womens Health (Larchmt). 2012;21:1031-7.

6. Kurman RJ, Carcangiu ML, Herrington CS, Young RH. WHO classification of tumours of female reproductive organs. 4th ed. Lyon: International Agency for Research on Cancer (IARC); 2014. 
7. Nishio S, Mikami $\mathrm{Y}$, Tokunaga $\mathrm{H}$, et al. Analysis of gastric-type mucinous carcinoma of the uterine cervix - An aggressive tumor with a poor prognosis: A multi-institutional study. Gynecol Oncol. 2019;153:13-9.

8. Kojima A, Mikami Y, Sudo T, Yamaguchi S, Kusanagi Y, Ito M, Nishimura R. Gastric morphology and immunophenotype predict poor outcome in mucinous adenocarcinoma of the uterine cervix. Am J Surg Pathol. 2007;31:664-72.

9. Lalit K, Sudeep G. Integrating Chemotherapy in the Management of Cervical Cancer: A Critical Appraisal. Oncology. 2016;91(suppl 1):8-17.

10. Mariateresa Lapresa G, Parma RP, Nicoletta Colombo. Neoadjuvant chemotherapy in cervical cancer: an update. Expert Rev Anticancer Ther. 2015;15(10):1171-81.

11. Emily M, Marisa N. Peutz-Jeghers Syndrome Pathobiology, Pathologic Manifestations, and Suggestions for Recommending Genetic Testing in Pathology Reports. Surgical Pathology. 2016;9:243-68.

12. Jeghers $\mathrm{H}$, McKusick KV, Katz KH. Generalized intestinal polyposis and melanin spots of the oral mucosa, lips and digits; a syndrome of diagnostic significance. N Engl J Med. 1949;241(26):1031-6.

13. Riegert-Johnson D, Ferga CG, Westra W, et al. Peutz-jeghers syndrome. In: Riegert-Johnson DL.

14. Boardman LA, Hefferon T et al, editors. Cancer syndromes. Bethesda (MD): National Center for Biotechnology Information; 2009.

15. Beggs AD, Latchford AR, Vasen HF, Moslein G, Alonso A, Aretz S, Bertario L, Blanco I, Bülow S, Burn J, Capella G, Colas C, Friedl W, Møller P, Hes FJ, Järvinen H, Mecklin JP, Nagengast FM, Parc Y, Phillips RK, Hyer W, Ponz de Leon M, Renkonen-Sinisalo L, Sampson JR, Stormorken A, Tejpar S, Thomas HJ, Wijnen JT, Clark SK, Hodgson SV. Peutz-Jeghers syndrome: a systematic review and recommendations for management. Gut. 2010;59:975-86. PubMed PMID: 20581245.

16. Jenne DE, Reimann H, Nezu J, et al. Peutz-Jeghers syndrome is caused by mutations in a novel serine threonine kinase. Nat Genet. 1998;18(1):38-43.

17. Aretz S, Stienen D, Uhlhaas S, et al. High proportion of large genomic STK11 deletions in PeutzJeghers syndrome. Hum Mutat. 2005;26(6):513-9. doi:10.1002/humu.20253.

18. Julian Daniell J-P, Plazzer A, Perera, et al. An exploration of genotype-phenotype link between PeutzJeghers syndrome and STK11: a review. Fam Cancer. 2018;17:421-7.

19. McGarrity TJ, Kulin HE, Zaino RJ. Peutz-Jeghers syndrome. Am J Gastroenterol. 2000;95(3):596604.

20. Banno K, Kisu I, Yanokura M, et al. Hereditary gynecological tumors associated with Peutz-Jeghers syndrome (Review). Oncol Lett. 2013;6(5):1184-8.

21. Karuna, Garg. Anthony Karnezis and Joseph Rabban. Uncommon hereditary gynaecological tumour syndromes: pathological features in tumours that may predict risk for a germline mutation. Pathology (February. 2018;50(2):238-56. 
22. Ferry JA, Young RH, Engel G, et al. Oxyphilic Sertoli cell tumor of the ovary: a report of three cases, two in patients with the Peutz-Jeghers syndrome. Int J Gynecol Pathol. 1994;13:259-66.

23. Gilks CB, Young RH, Aguirre P, et al. Adenoma malignum (minimal deviation adenocarcinoma) of the uterine cervix. A clinicopathological and immunohistochemical analysis of 26 cases. Am J Surg Pathol. 1989;13:717-29.

24. Chen KT. Female genital tract tumors in Peutz-Jeghers syndrome. Hum Pathol. 1986;17:858-61.

25. Giardiello FM, Brensinger JD, Tersmette AC, et al. Very high risk of cancer in familial Peutz-Jeghers syndrome. Gastroenterology. 2000;119:1447-53.

26. Kawakami F, Mikami Y, Kojima A, Ito M, Nishimura R, Manabe T. Diagnostic reproducibility in gastrictype mucinous adenocarcinoma of the uterine cervix: validation of novel diagnostic criteria. Histopathology. 2010;56:551-3.

27. Zhang $Y$, Liang $L$, Euscher $E$, et al. Gastric-type mucinous adenocarcinoma of the uterine cervix with neoadjuvant therapy mimicking clear cell carcinoma. Int J Clin Exp Pathol. 2015;8(9):11798-803.

28. Kojima A, Mikami Y, Sudo T, et al. Gastric morphology and immunophenotype predict poor outcome in mucinous adenocarcinoma of the uterine cervix. Am J Surg Pathol. 2007;31:664-72.

29. Nara M, Hashi A, Murata S, et al. Lobular endocervical glandular hyperplasia as a presumed precursor of cervical adenocarcinoma independent of human papillomavirus infection. Gynecol Oncol. 2007;106:289-98.

30. Kusanagi Y, Kojima A, Mikami Y, et al. Absence of high-risk human papillomavirus (HPV) detection in endocervical adenocarcinoma with gastric morphology and phenotype. Am J Pathol. 2010;177:2169-75.

31. Wada T, Ohishi Y, Kaku T, et al. Endocervical adenocarcinoma with morphologic features of both usual and gastric types: clinicopathologic and immunohistochemical analyses and high-risk HPV detection by in situ hybridization. Am J Surg Pathol. 2017;41:696-705.

32. Park KJ, Kiyokawa T, Soslow RA, et al. Unusual endocervical adenocarcinomas: an immunohistochemical analysis with molecular detection of human papillomavirus. Am J Surg Pathol. 2011;35:633-46.

\section{Tables}


Table 1

Cumulative Risk of Cancers in Peutz-Jeghers Syndrome

\begin{tabular}{|llll|}
\hline \multirow{2}{*}{ Cancer site } & General population risk & \multicolumn{2}{l|}{ Peutz-Jeghers syndrome } \\
\cline { 3 - 4 } & & Risk & Mean age at diagnosis \\
\hline Colorectal & $5 \%$ & $39 \%$ & $42-46$ years \\
\hline Stomach & $<1 \%$ & $29 \%$ & $30-40$ years \\
\hline Small Bowel & $<1 \%$ & $13 \%$ & $37-42$ years \\
\hline Ovarian(mostly SCTAT) & $1.6 \%$ & $21 \%$ & 28 years \\
\hline Cervix(adenoma malignum) & $<1 \%$ & $10 \%$ & $34-40$ years \\
\hline Uterus & $2.7 \%$ & $9 \%$ & 43 years \\
\hline Pancreas & $1.5 \%$ & $11 \%-36 \%$ & $41-52$ years \\
\hline Testicular(Sertoli cell tumor) & $<1 \%$ & $9 \%$ & $6-9$ years \\
\hline Lung & $6.9 \%$ & $7 \%-17 \%$ & 47 years \\
\hline Breast & $12.4 \%$ & $32 \%-54 \%$ & $37-59$ years \\
\hline SCTAT: sex cord tumour with annular tubules & & \\
\hline
\end{tabular}


Table 2

Screening and Surveillance Guidelines for Peutz-Jeghers Syndrome

\begin{tabular}{|c|c|c|c|}
\hline Site & Procedure & $\begin{array}{l}\text { Age at Initial } \\
\text { Screening(yr) }\end{array}$ & Interval \\
\hline Stomach & Upper endoscopy & $8,18^{1}$ & $3 \mathrm{yrs}^{1}$ \\
\hline $\begin{array}{l}\text { Small } \\
\text { intestine }\end{array}$ & Capsule endoscopy or $\mathrm{MRE}^{2}$ & $8,18^{3}$ & 3 yrs \\
\hline $\begin{array}{l}\text { Large } \\
\text { intestine }\end{array}$ & Colonoscopy & $8,18^{1}$ & $3 \mathrm{yrs}^{1}$ \\
\hline \multirow[t]{3}{*}{ Breast } & Breast self-examination & 18 & $1 \mathrm{x} / \mathrm{mo}$ \\
\hline & Clinical breast exam & & $6 \mathrm{mos}$ \\
\hline & Breast MRI or digital mammography $4,5,6$ & 25 & $1 \mathrm{yr}$ \\
\hline $\begin{array}{l}\text { Ovary, } \\
\text { cervix,uterus }\end{array}$ & $\begin{array}{l}\text { Transvaginal ultrasound \& serum CA 125;pelvic } \\
\text { exam w/pap smear }{ }^{6}\end{array}$ & $18-20$ & $1 \mathrm{yr}$ \\
\hline Pancreas & MRI-MRCP or endoscopic ultrasound & 30 & $\begin{array}{l}1-2 \\
\text { yrs }\end{array}$ \\
\hline Testes & $\begin{array}{l}\text { Testicular exam; ultrasound if symptomatic or } \\
\text { abnormality on exam }\end{array}$ & Birth to teen yrs & $1 \mathrm{yr}$ \\
\hline
\end{tabular}

\section{Figures}



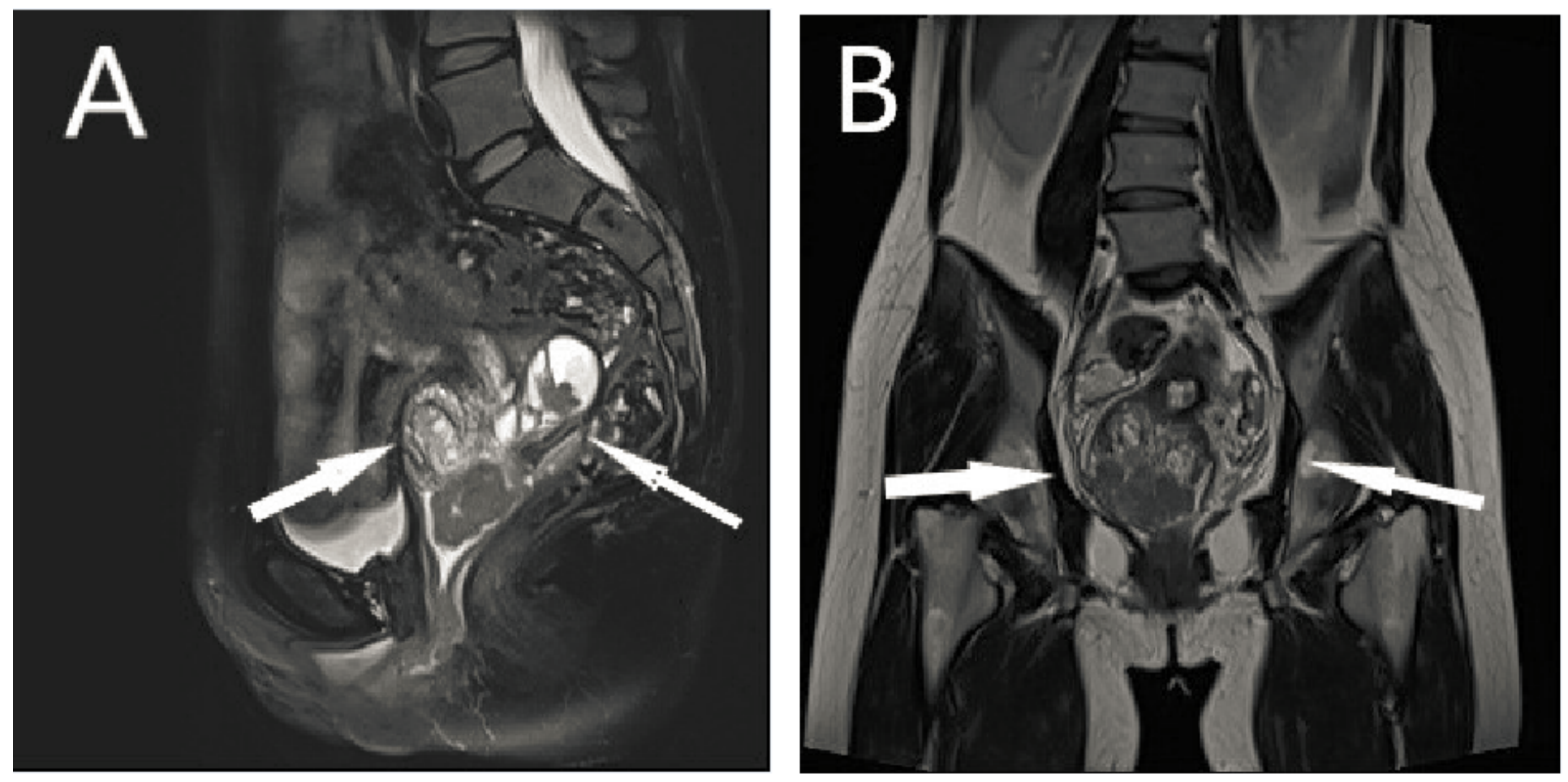

Figure 1

$(A, B)$ Pelvic magnetic resonance image showing a tumor of the cervix with cystic lesions (arrow). 


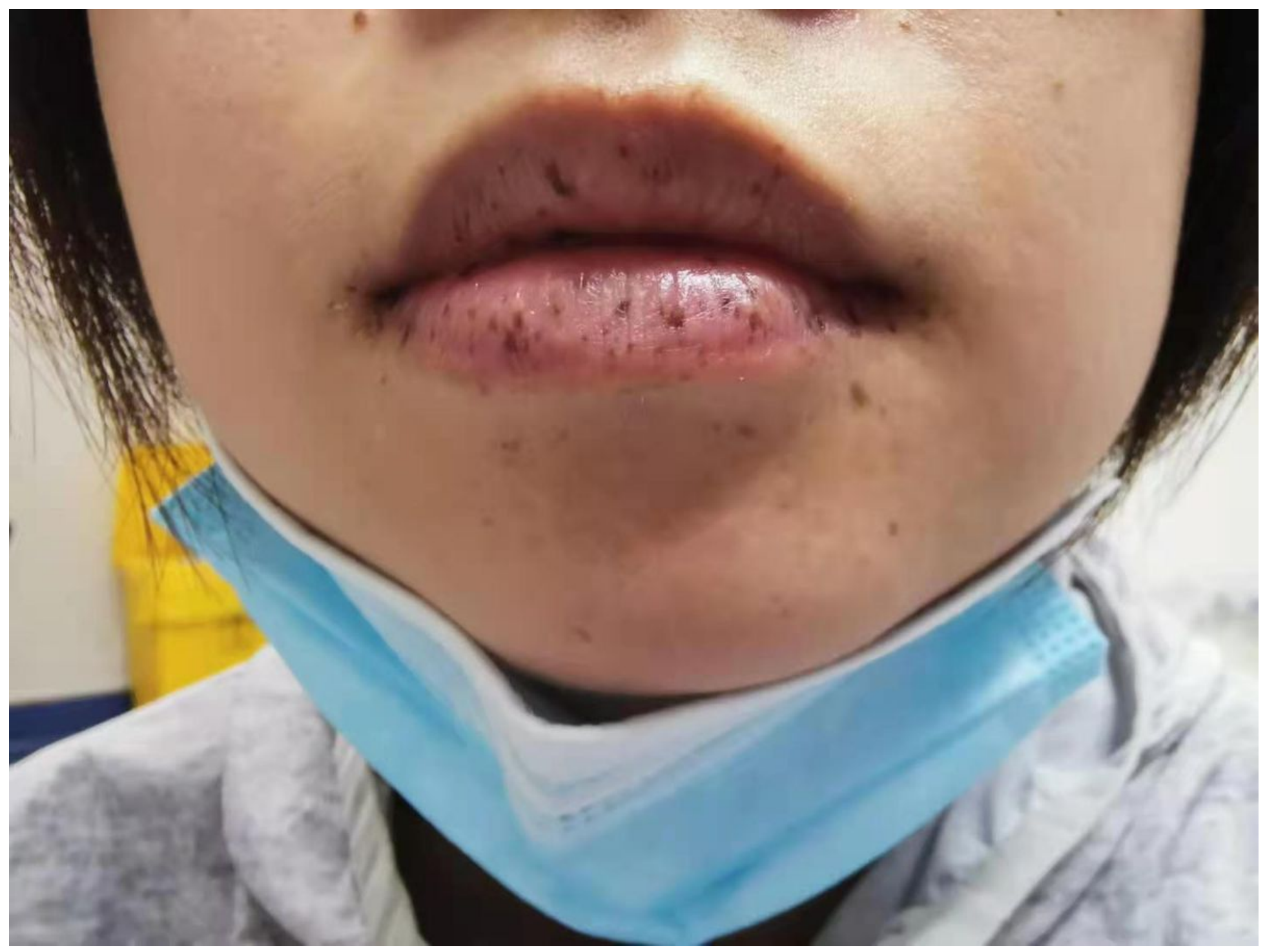

Figure 2

Peutz-Jeghers syndrome patient with pigmentations over the lips, especially the lower lip and nostrils.

A

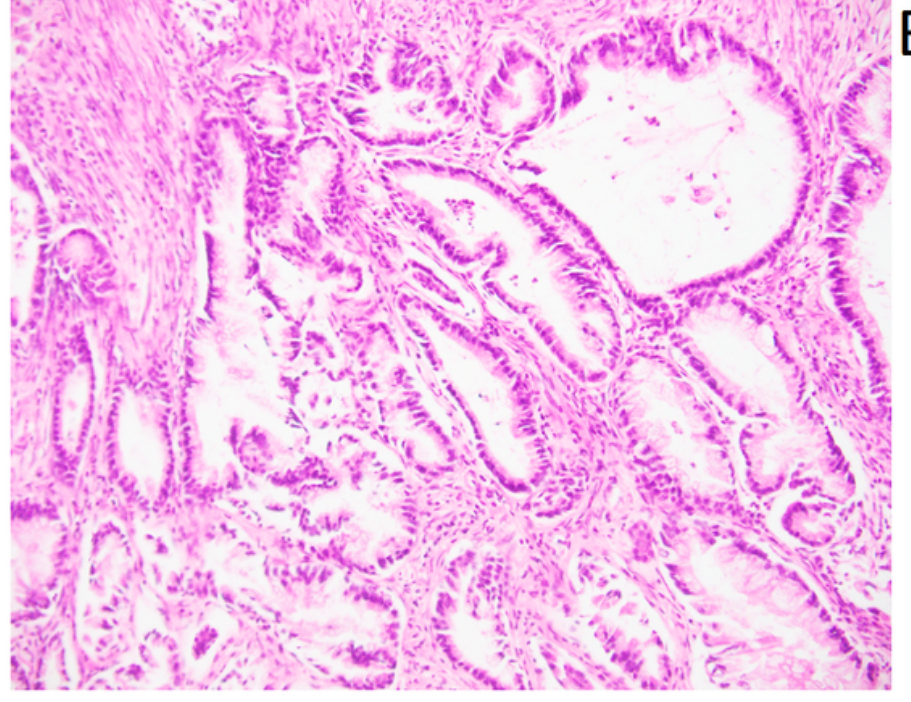

B F pars

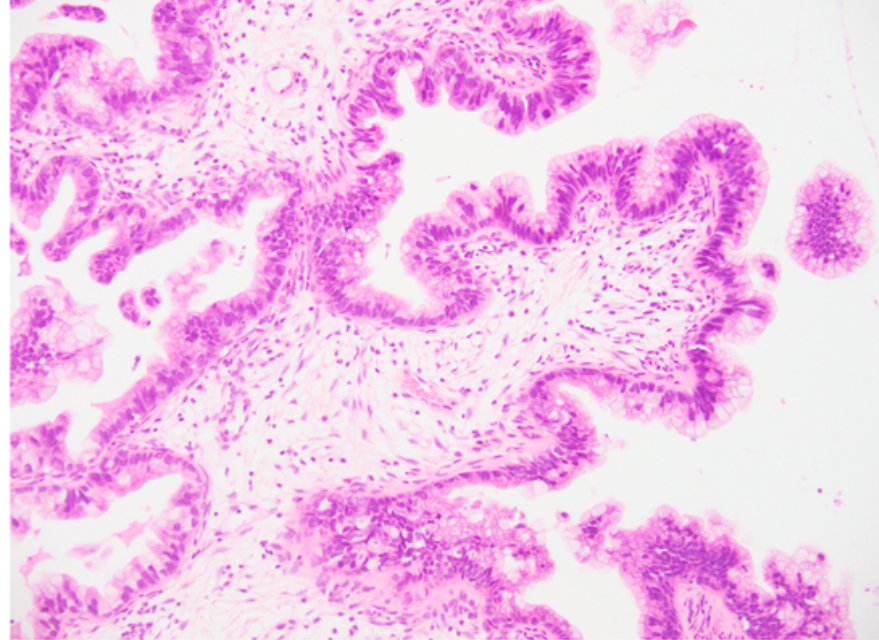


Figure 3

$(A, B)$ Histopathological results of radical surgery.
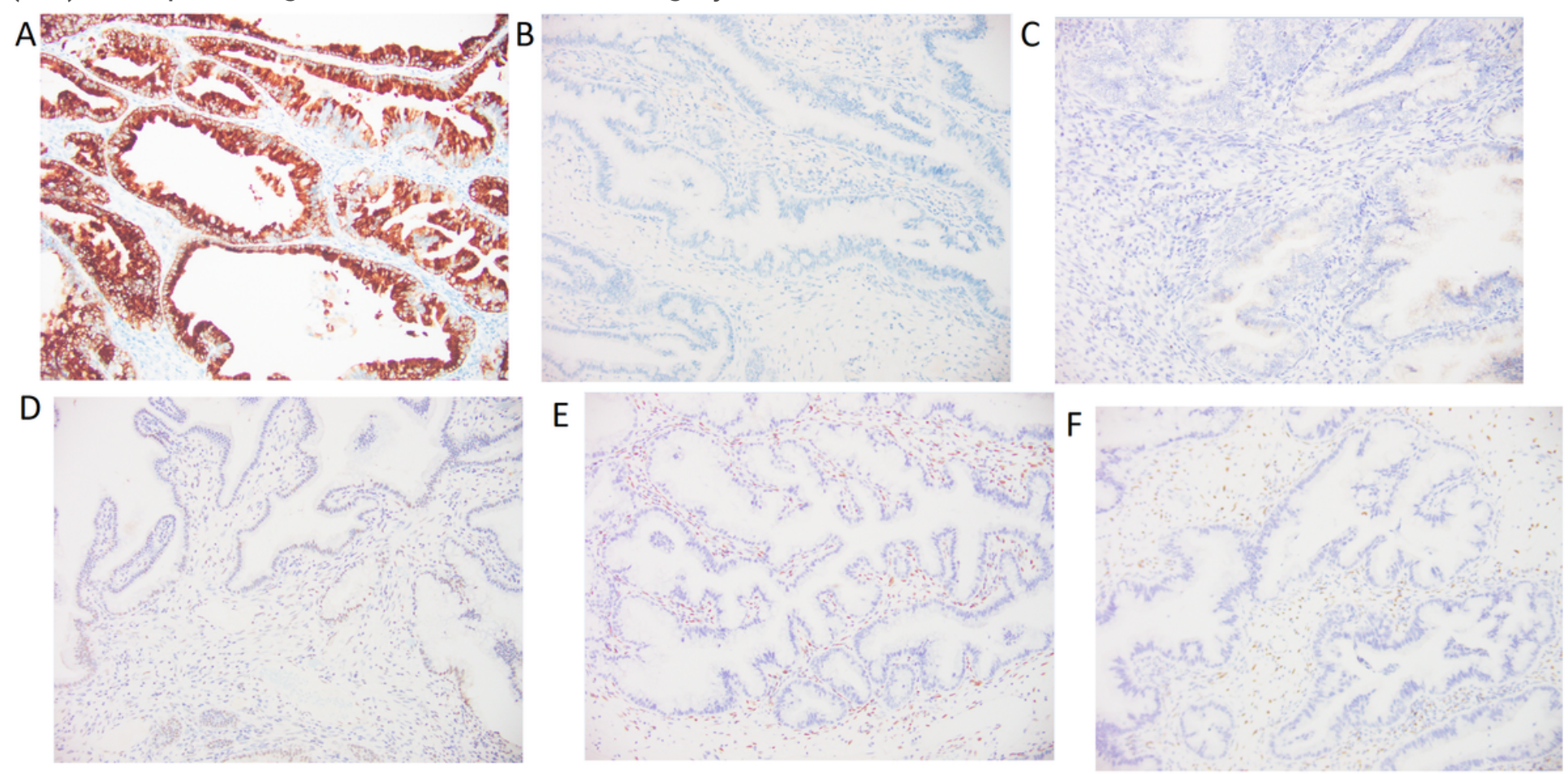

\section{Figure 4}

(A) Immunohistochemical staining is positive for MUC6, a marker of pyloric gland mucin; (B) Immunohistochemical staining is negative for MUC2; (C) Immunohistochemical staining is patchy for P16; $(D, E, F)$ Immunohistochemical staining is negative for P53, ER and PR. 